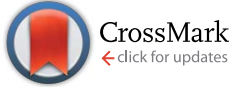

Cite this: RSC Adv., 2017, 7, 11271

Received 25th November 2016 Accepted 4th February 2017

DOI: $10.1039 / c 6 r a 27345 a$

rsc.li/rsc-advances

\section{Development of functionalized abamectin poly(lactic acid) nanoparticles with regulatable adhesion to enhance foliar retention $\uparrow$}

\author{
Manli Yu, Junwei Yao, Jie Liang, Zhanghua Zeng, ${ }^{*}$ Bo Cui, Xiang Zhao, Changjiao Sun, \\ Yan Wang, Guogiang Liu and Haixin Cui*
}

Pesticides are important to defend against biological disasters and ensure food security. Most conventional pesticide formulations suffer from heavy losses to the surrounding environment and low effective utilization rate, leading to the pollution of ecological systems and food because of their weak adhesion to crop foliage. To increase both the adhesion to foliage and effective utilization rate of pesticides, we developed three types of functionalized abamectin poly(lactic acid) (Abam-PLA) nanoparticles $\left(\mathrm{CH}_{3} \mathrm{CO}-\mathrm{PLA}-\mathrm{NS}, \mathrm{HOOC}\right.$ PLA-NS and $\mathrm{H}_{2} \mathrm{~N}$-PLA-NS) with different adhesion abilities to cucumber foliage. The Abam-PLA nanoparticles were spherical with diameters of around $450 \mathrm{~nm}$, and their maximum abamectin loading rate was around $50 \%$. The nanoparticles exhibited better continuous release behavior and photostability compared with active abamectin. The Abam-PLA nanoparticles showed favorable deposition on the surface of cucumber foliage, and their adhesion to cucumber foliage surface followed the order: $\mathrm{H}_{2} \mathrm{~N}$ PLA-NS > $\mathrm{CH}_{3} \mathrm{CO}-\mathrm{PLA}-\mathrm{NS}>\mathrm{HOOC}$-PLA-NS. The adhesion of the nanoparticles to the foliage surface strongly depended on the functional groups on the nanoparticle surface. $\mathrm{H}_{2} \mathrm{~N}$-PLA-NS interacted with the cucumber foliage surface by hydrogen bond, electrostatic attraction, and covalent bond. In contrast, HOOC-PLA-NS interacted with the cucumber foliage through hydrogen bond and electrostatic repulsion. Regulatable adhesion could be achieved by tuning the interaction mode between the nanoparticles and foliage surface. This study provided a visual method to better understand the interaction mechanism between nanoparticles and crop foliage. Our results will be helpful to develop pesticide nanoparticles with strong adhesion to foliage, improving the effective utilization rate and bioavailability of pesticides.

\section{Introduction}

Pesticides play an important role in protecting crops from biological disasters and yield loss. ${ }^{1}$ According to data from the United Nations Food and Agriculture Organization, more than $30 \%$ of the total crop production around the world annually is saved by pesticides. ${ }^{2,3}$ However, the amount of pesticides used exceeds 2.4 million tons per year globally. ${ }^{4}$ Pesticides have been widely used and improperly disposed of, leading to long-term accumulative contamination of water, soil, and even agricultural products, and pose acute toxicity risks to people and animals exposed to large amounts. ${ }^{5-10}$ Although some pesticide compounds decompose rapidly on exposure to light, water, soil, and air, they can be always detected in agricultural products and drinking water. ${ }^{\mathbf{1 1}, \mathbf{1 2}}$ An excessive content of pesticides in soil,

Institute of Environment and Sustainable Development in Agriculture, Chinese Academy of Agricultural Sciences, Beijing, 100081, PR China. E-mail: zengzhanghua@caas.cn; cuihaixin@caas.cn; Tel: +86-1082106004

$\dagger$ Electronic supplementary information (ESI) available. See DOI: 10.1039/c6ra27345a water, food, vegetables, and fruits not only threatens human health, but also causes pest resistance, which can damage the ecological environment and biodiversity. ${ }^{\mathbf{1 3 - 1 5}}$

Most pesticide formulations are applied as sprays. For the spray pesticides, pesticides are firstly deposited on crop foliage, and then they go to parts of the plant attacked by a pest through diffusion, uptake and/or transfer processes, leading to pest poisoning or death by active or passive contact. It has been reported that the effective utilization rate of conventional pesticide formulations to crop foliage is usually less than $10 \%$, and most of the pesticides ends up in the surrounding environment because of weak adhesion to the crop foliage. ${ }^{16}$ The pesticides overdosage gives rise to undesirable side effects in ecological environment. Therefore, a stable and controlled release pesticide formulation with high affinity for crop foliage and long retention time on crop foliage will be highly desirable to increase the effective utilization rate of pesticides and minimize loss to the environment.

In recent years, the rapid development of nanotechnology has provided a new way to improve the performance of pesticide formulations by constructing nanoparticle-based pesticide 


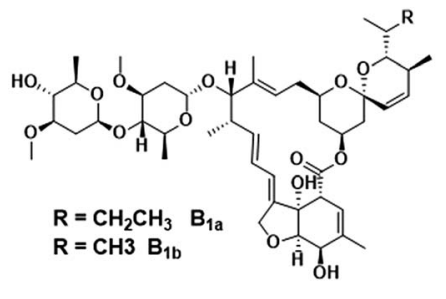

Abamectin

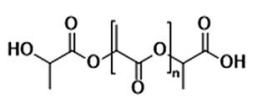

Poly(lactic acid) (PLA)
Fig. 1 The chemical structure of abamectin and PLA.

delivery systems. ${ }^{17-29}$ It has proved that the nanopesticide formulations have better pest control efficacy over commercially available pesticide formulations. ${ }^{16,20,21}$ The vast majority of nanopesticides research is focused on the construction of smart controlled release formulations. ${ }^{18-28}$ Although interaction between nanopesticides and crop foliage is very import because of most of pesticides sprayed on crop foliages, very few researches have paid attention to it so far. Compared with conventional pesticide formulations, nanopesticides exhibit smaller size and have larger surface area, which can improve the deposition on crop foliage and prolong the sustained pesticide release time..$^{30,31}$ In addition, by introducing affinity group on the surface of nanopesticides, the adhesion to crop foliages has be significantly improved, and the pesticide loss from foliage has be substantially reduced. ${ }^{32}$

Abamectin is a mixture of avermectins (around $80 \%$ avermectin $\mathrm{B}_{1 \mathrm{a}}$ and $20 \%$ avermectin $\mathrm{B}_{1 \mathrm{~b}}$ ) (Fig. 1). It is a pesticide from the soil bacterium Streptomyces avermitilis, and is one of most used biocides to control pests of a range of agronomic, vegetable and fruit crops ${ }^{33}$ However, abamectin is easily degraded by direct solar irradiation, resulting in short half-time and low utilization rate. ${ }^{34}$ Hence, a facile way to encapsulate abamectin by biodegradable material is desirable to improve its photostability. Pol$y$ (lactic acid) (PLA) is able to degrade into innocuous lactic acid, and PLA based nanoparticles are widely used as biodegradable drug carrier. The abamectin could be protected from light irradiation after encapsulation by PLA nanoparticles.

Here, weakly hydrophilic cucumber foliage was selected as an experimental model. We developed three types of abamectin and PLA (Abam-PLA) nanoparticles functionalized with various groups. We demonstrated the regulatable adhesion of these nanoparticles to cucumber foliage simply by changing the interaction mode between the functional groups of the AbamPLA nanoparticles and those of the cucumber foliage surface.

\section{Experimental sections}

\section{Materials and instruments}

PLA ( $M_{\mathrm{w}}$ approximately 100000$)$ was purchased from Daigang Biomaterial Company, China. Abamectin (95.6\%) was purchased from Qilu Pharmaceutical Company, Ltd., China. Poly(vinyl alcohol) (PVA) was purchased from Sigma Aldrich. Rhodamine 6G (98.5\%) and dichloromethane $\left(\mathrm{CH}_{2} \mathrm{Cl}_{2}, 99.8 \%\right)$ were purchased from Bailingwei Technology Company, Ltd., China. Commercially available water-dispersible granules
(WDG) and emulsifiable concentrate (EC) were obtained from Nuopuxin Company, Ltd., China. All chemicals were directly used as received without further purification unless otherwise mentioned. Cucumber foliage was carefully selected 21 days after seeding to ensure reproducibility.

UV-Vis absorption spectra were measured on a UV-2600 spectrophotometer (Shimadzu). Fluorescence spectra were measured on a F4600 fluorometer (Hitachi). The morphology of Abam-PLA nanoparticles was examined by a scanning electron microscope (SEM; JSM-7401 F, JEOL Ltd., Akishima-shi, Japan). To prepare samples for SEM investigation, $\mathrm{CH}_{3}$ CO-PLA-NS, HOOC-PLA-NS and $\mathrm{H}_{2} \mathrm{~N}$-PLA-NS nanoparticles $\left(1.0 \mathrm{mg} \mathrm{mL}^{-1}\right)$ were suspended in deionized water and ultrasonicated for $1 \mathrm{~min}$. Abam-PLA nanoparticle suspension $(10 \mu \mathrm{L})$ was added dropwise onto the surface of a polished silicon substrate, and naturally dried at room temperature (RT) overnight before capturing SEM images. The hydrodynamic size distribution, polydispersity index

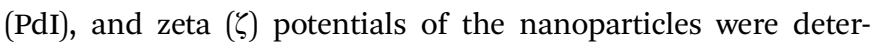
mined by photon correlation spectroscopy using a particle size analyzer (Nano-ES90, Malvern Instruments, UK). Each nanoparticle sample was analyzed in triplicate to ensure reproducibility, and the average value is reported. Confocal fluorescence images were obtained on a laser scanning confocal microscope (LSCM; LSM 710, Carl Zeiss, Germany). Environmental scanning electron microscope (ESEM) images of Abam-PLA nanoparticles were recorded on a SEM (Quanta FEG 250, FEI, USA). In vivo fluorescence images of the cucumber foliage were obtained by an in vivo measurement system (Spectrum, Caliper, USA).

\section{Synthesis of $\mathrm{CH}_{3} \mathrm{CO}-\mathrm{PLA}$}

HO-PLA-COOCH${ }_{2} \mathrm{CH}_{3}(10 \mathrm{~g}, 0.1 \mathrm{mM})$ was suspended and slowly dissolved in $\mathrm{CH}_{2} \mathrm{Cl}_{2}(100 \mathrm{~mL})$ over $1 \mathrm{~h}$, and then triethylamine (15 mg, $0.15 \mathrm{mM})$ in $\mathrm{CH}_{2} \mathrm{Cl}_{2}(5 \mathrm{~mL})$ was slowly added. Acetyl chloride $(9.4 \mathrm{mg}, 0.12 \mathrm{mM})$ in $\mathrm{CH}_{2} \mathrm{Cl}_{2}(5 \mathrm{~mL})$ was added dropwise over $20 \mathrm{~min}$ to this mixture in an ice-water bath. The mixed solution was allowed to warm to RT, and then stirred for $4 \mathrm{~h}$ at RT. The reaction solution was extracted with $1.0 \%(\mathrm{w} / \mathrm{w}) \mathrm{NaHCO}_{3}$ and distilled water twice. The organic phase was collected and dried with anhydrous $\mathrm{Na}_{2} \mathrm{SO}_{4}$ overnight. The organic solvent was evaporated under vacuum to afford $\mathrm{CH}_{3}$ CO-PLA (9.2 g, yield: $92 \%$ ).

\section{Synthesis of HOOC-PLA}

OH-PLA-COOH (10 g, $0.1 \mathrm{mM})$ was suspended and slowly dissolved in $\mathrm{CH}_{2} \mathrm{Cl}_{2}(100 \mathrm{~mL})$ over $1 \mathrm{~h}$, and then triethylamine $(15 \mathrm{mg}$, $0.15 \mathrm{mM})$ in $\mathrm{CH}_{2} \mathrm{Cl}_{2}(5 \mathrm{~mL})$ was slowly added. Acetyl chloride (9.4 mg, $0.12 \mathrm{mM})$ in $\mathrm{CH}_{2} \mathrm{Cl}_{2}(5 \mathrm{~mL})$ was added dropwise over $20 \mathrm{~min}$ to this mixture in an ice-water bath. The mixed solution was allowed to warm to RT, and then stirred for $4 \mathrm{~h}$ at RT. The reaction solution was extracted with $1.0 \%(\mathrm{w} / \mathrm{w}) \mathrm{NaHCO}_{3}$ and distilled water twice. The organic phase was collected and dried with anhydrous $\mathrm{Na}_{2} \mathrm{SO}_{4}$ overnight. The organic solvent was evaporated under vacuum to afford HOOC-PLA (9.3 g, yield: 93\%).

\section{Synthesis of $\mathbf{H}_{2} \mathbf{N}$-PLA}

OH-PLA-COOH (10 g, $0.1 \mathrm{mM})$ was suspended and slowly dissolved in $\mathrm{CH}_{2} \mathrm{Cl}_{2}(100 \mathrm{~mL})$ over $1 \mathrm{~h}$. Hydroxysuccinimide $(0.14 \mathrm{~g}$, 
$0.12 \mathrm{mM}$ ) was directly added, and then 1-ethyl-3-(3dimethylaminopropyl)carbodiimide $\mathrm{HCl}(0.24 \mathrm{~g}, 0.12 \mathrm{mM})$ was added to the mixed solution. The reaction solution was stirred at RT for $4 \mathrm{~h}$. The insoluble residue was filtered off, and then the filtrate was extracted with weakly acidic water $(\mathrm{pH}=5.0)$ three times and then weakly basic water $\left(1.0 \%(\mathrm{w} / \mathrm{w}) \mathrm{NaHCO}_{3}\right)$ three times. The organic phase was collected and dried with anhydrous $\mathrm{Na}_{2} \mathrm{SO}_{4}$ overnight. The organic solvent was evaporated under vacuum to afford NHS-PLA (9.1 g, yield: 91\%).

The obtained NHS-PLA ( $9 \mathrm{~g}, 0.09 \mathrm{mM})$ was slowly dissolved in $\mathrm{CH}_{2} \mathrm{Cl}_{2}(100 \mathrm{~mL})$ over $1 \mathrm{~h}$, and then $N$-Boc-ethylenediamine $(0.16 \mathrm{~g}, 0.1 \mathrm{mM})$ in $\mathrm{CH}_{2} \mathrm{Cl}_{2}(5 \mathrm{~mL})$ was added dropwise over $10 \mathrm{~min}$. The reaction solution was stirred for $6 \mathrm{~h}$, and then the insoluble solid was filtered off. The filtrate was extracted with weakly acidic water $(\mathrm{pH}=5.0)$ three times. The organic phase was collected and dried with anhydrous $\mathrm{Na}_{2} \mathrm{SO}_{4}$ overnight. The organic solvent was evaporated under vacuum to afford Boc-NHPLA (8.1 g, yield: 90\%).

The obtained Boc-NH-PLA (8.1 g, $0.08 \mathrm{mM})$ was slowly dissolved in a mixture of $\mathrm{CH}_{2} \mathrm{Cl}_{2}$ and trifluoroacetic acid $(3 / 2, \mathrm{v} / \mathrm{v})$ in an ice-water bath. The mixed solution was stirred for $2 \mathrm{~h}$ at this temperature, and then warmed naturally to RT. After stirring for $2 \mathrm{~h}$ at RT, the organic solvent was evaporated under high vacuum to give $\mathrm{H}_{2} \mathrm{~N}-\mathrm{PLA}$ ( $8 \mathrm{~g}$, yield: $100 \%$ ).

\section{Preparation of Abam-PLA nanoparticles}

Abamectin (0.4 g), $\mathrm{CH}_{3} \mathrm{CO}-\mathrm{PLA}(0.4 \mathrm{~g})$, and rhodamine 6G (0.016 g) were slowly dissolved in $\mathrm{CH}_{2} \mathrm{Cl}_{2}(10 \mathrm{~mL})$ at RT by magnetic stirring. The solution was added dropwise over $5 \mathrm{~min}$ to PVA solution $\left(0.01 \mathrm{~g} \mathrm{~mL}^{-1}\right)$ that was used as a surfactant, and the system was stirred vigorously $(1000 \mathrm{rpm})$ for $1 \mathrm{~h}$. The primary mixture was emulsified by ultrasonication for $240 \mathrm{~s}$ in intervals of $20 \mathrm{~s}$ with a $10 \mathrm{~s}$ pause between at $70 \%$ amplitude using a sonifier (JY90-IIN, Ningbo Scientz Biotechnology Company, Ltd.) while being cooled in an ice-water bath to prevent the evaporation of $\mathrm{CH}_{2} \mathrm{Cl}_{2}$. The solution was then stirred for $24 \mathrm{~h}$ at RT, allowing the organic solvent to naturally evaporate. The resulting suspension was centrifuged at $10000 \mathrm{rpm}$ for $10 \mathrm{~min}$ at $4{ }^{\circ} \mathrm{C}$. The pellet was collected and redispersed in deionized water. This process was repeated three times until fluorescence of the supernatant layer was not detected by the naked eye using a handheld UV lamp irradiated at $365 \mathrm{~nm}$. The collected pellet was lyophilized to give fluorescent $\mathrm{CH}_{3} \mathrm{CO}-\mathrm{PLA}-\mathrm{NS}$. Nonfluorescent $\mathrm{CH}_{3} \mathrm{CO}$-PLA-NS was prepared by following the same procedure except that rhodamine $6 \mathrm{G}$ was omitted.

HOOC-PLA-NS and $\mathrm{H}_{2} \mathrm{~N}$-PLA-NS were prepared following a similar synthetic route to that of $\mathrm{CH}_{3} \mathrm{CO}-\mathrm{PLA}-\mathrm{NS}$.

\section{Determination of the loading rate of Abam-PLA nanoparticles}

The abamectin loading rate (ALR) of the Abam-PLA nanoparticles was determined as follows. An appropriate amount of Abam-PLA nanoparticles $\left(M_{0}\right)$ was dispersed in $\mathrm{CH}_{2} \mathrm{Cl}_{2}(5 \mathrm{~mL})$ and sonicated for $5 \mathrm{~min}$ at RT. The insoluble residue was filtered off, and the filtrate was diluted to a proper volume $(V)$ with $\mathrm{CH}_{2} \mathrm{Cl}_{2}$. The absorbance of the solution at $245 \mathrm{~nm}$ was measured on a UV-Vis spectrophotometer (UV-2600, Shimadzu, Kyoto, Japan) to determine the abamectin concentration $(C)$, which was obtained from the calibration curve. ALR was determined using the following equation,

$$
\mathrm{ALR}=\left(C \times V \times M_{\mathrm{w}}\right) / M_{0} \times 100 \%
$$

where $M_{\mathrm{w}}$ is molecular weight of abamectin.

\section{Sustained release behavior of Abam-PLA nanoparticles}

Abam-PLA nanoparticles (20 mg) were suspended in $60 \%$ methanol/phosphate-buffered saline (PBS; $\mathrm{pH}=7.4,100 \mathrm{~mL}$ ). The suspension was carefully transferred to different dialysis bags (2000 MWCO). After sealing tightly, the bags were put into $60 \%$ methanol/PBS solution $(95 \mathrm{~mL})$ as the release media. The released abamectin was determined by collecting $5 \mathrm{~mL}$ aliquots of the release media outside the dialysis bags after 1 , $2,3,5,7,11,20,28,36,45,55,76,120,144,168,192$, and 216 h. $C$ was determined from the calibration curve by measuring the absorbance of each aliquot at $245 \mathrm{~nm}$ using the UV-2600 spectrophotometer. The accumulated release percentages were obtained versus time from the sustained release amounts. At the same time, the active abamectin was measured for comparison.

\section{Photodegradation behavior of Abam-PLA nanoparticles}

Abam-PLA nanoparticles (50 mg) were irradiated at RT by a $365 \mathrm{~nm}$ light incubator (XT5409-XPC80, $400 \mathrm{~W}$, Xutemp Technic Apparatus Co., Ltd., China). The samples revolved around the light source at a distance of $10 \mathrm{~cm}$. Samples $(10 \mathrm{mg})$ were collected at specific time intervals. The photodegradation behavior of abamectin after different irradiation times was analyzed by measuring the absorbance of each sample at $245 \mathrm{~nm}$. At same time, the active abamectin was tested for comparison.

\section{Contact angle measurement of Abam-PLA nanoparticles}

Live cucumber foliage obtained from a light incubator was flushed gently several times with deionized water to remove any dust on its surface. This cleaning was performed very carefully to ensure that the structure of the foliage was not damaged. After natural drying in air, some parts of the foliage were cut and adhered smoothly to glass slides for use as the experimental leaf surface. The glass slides were placed on the object stage of a contact angle (CA) instrument (JC2000D2M, Zhongchen Digital Technic Apparatus Company, Ltd., China), and aqueous solutions of Abam-PLA nanoparticles $\left(5.0 \mu \mathrm{L}, 1 \mathrm{mg} \mathrm{L}^{-1}\right)$ were added dropwise onto the foliage. Images of each droplet on the foliage surface were captured, and the corresponding CA values were calculated. Given the data reliability and complexity of a cucumber leaf surface, measurements were repeated at least five times and the average values are reported. The CA of deionized water was determined for comparison.

\section{LSCM images of Abam-PLA nanoparticles}

Live cucumber foliage obtained from a light incubator was flushed gently several times with deionized water to remove any dust on its surface. This cleaning process was performed very carefully to ensure that the foliage structure was not damaged. 
After natural drying in air, an aqueous solution of fluorescent Abam-PLA nanoparticles $\left(500 \mu \mathrm{L}, 3.0 \mathrm{mg} \mathrm{mL} \mathrm{mL}^{-1}\right)$ was sprayed onto the surface of the cucumber foliage. After drying in air, some parts of the foliage were cut into slices and adhered smoothly onto glass slides for use as experimental foliage samples. The leaf samples were subjected to LSCM imaging (LSM 710, Carl Zeiss, Germany) at excitation wavelengths of $555 \mathrm{~nm}$ (rhodamine 6G) and $630 \mathrm{~nm}$ (chlorophyll). Afterwards, the same leaf slice samples were washed with deionized water $(100 \mathrm{~mL})$, dried, and then imaged by LSCM again.

\section{ESEM images of Abam-PLA nanoparticles}

Fluorescent nanoparticles $\left(500 \mu \mathrm{L}, 3.0 \mathrm{mg} \mathrm{mL}^{-1}\right)$ were sprayed onto the surfaces of clean live cucumber leaves prepared as described above. After drying in air, some parts of the leaves were cut into slices and used as experimental samples for ESEM measurement at $900 \mathrm{~Pa}$ and $10 \mathrm{kV}$. The used samples were washed with deionized water $(100 \mathrm{~mL})$, dried, and then further ESEM measurements were carried out.

\section{In vivo foliage imaging of Abam-PLA nanoparticles}

Fluorescent nanoparticles $\left(500 \mu \mathrm{L}, 3.0 \mathrm{mg} \mathrm{mL}^{-1}\right)$ were sprayed onto the surfaces of washed live cucumber leaves. After naturally drying in air, the full leaves on a plant were imaged by excitation at $535 \mathrm{~nm}$ and detection at $580 \mathrm{~nm}$. Each leaf was flushed with deionized water $(100 \mathrm{~mL})$, and dried naturally in air. Leaf imaging was performed again, and their fluorescence intensity was recorded. Each experiment was repeated at least three times to ensure repeatability, and the average values are reported.

\section{Analysis of abamectin residue on cucumber foliage by high- performance liquid chromatography (HPLC)}

The same amount of abamectin in Abam-PLA nanoparticles, WDG, and EC were sprayed onto the clean surfaces of live cucumber leaves without any dust. Each leaf was divided into two equal portions. After natural drying in air, the leaf halves were washed with deionized water $(100 \mathrm{~mL})$. The leaves were cut into small thin pieces, and each piece was extracted using a Soxhlet apparatus with $\mathrm{CH}_{2} \mathrm{Cl}_{2}$ as the solvent for $24 \mathrm{~h}$. The organic phase was collected, and the insoluble solid was filtered off. The obtained filtrate was evaporated slowly under low vacuum at $\mathrm{RT}$ to afford a colored solid. To this solid was added a mixture of $\mathrm{CH}_{3} \mathrm{CN}, \mathrm{CH}_{3} \mathrm{OH}$, and $\mathrm{H}_{2} \mathrm{O}(5 \mathrm{~mL}, 80: 15: 5, \mathrm{v} / \mathrm{v} / \mathrm{v})$. The mixture was stirred for $1 \mathrm{~h}$ and then ultrasonicated for $10 \mathrm{~min}$ at RT. After filtering off the insoluble residue, the filtrate was subjected to analysis by HPLC.

\section{Biological efficacy test}

In this experiment, the leaf dipping method was used to evaluate the indoor toxicity of abamectin towards cucumber aphids. Abamectin contents of 1.625, 3.125, 6.25, 12.5, 25, 50, and $100 \mathrm{mg}$ $\mathrm{L}^{-1}$ were finely formulated in all kinds of abamectin test samples including Abam-PLA nanoparticles, commercially available WDG, and EC. Fresh cucumber leaves with a diameter of around $6 \mathrm{~cm}$ were fully immersed in each solutions for $10 \mathrm{~s}$. After natural drying in air, each treated leaf was placed in a culture dish, and 20 similar active aphids were singled out and then added to each dish. The dishes were sealed with microporous plastic wrap and incubated at a humidity of $75 \%$, temperature of $25^{\circ} \mathrm{C}$ and $16: 8$ (light : dark). The number of dead aphids was carefully counted after $48 \mathrm{~h}$. The regression equation, median lethal concentration $\left(\mathrm{LC}_{50}\right)$ and its $95 \%$ confidence interval were calculated using DPS v12.01 statistical software. Each experiment was conducted four times for each sample and average values are reported. Deionized water was also tested for comparison.

\section{Results and discussion}

\section{Preparation and characterization of Abam-PLA nanoparticles}

PLA derivatives with different functional groups were synthesized in several steps, as summarized in Scheme S1. $\dagger$ Nanoparticle characterization and synthetic procedure are provided in the ESI. $\dagger$ Three kinds of Abam-PLA nanoparticles, uncharged $\mathrm{CH}_{3}$ CO-PLA, carboxylic acid-functionalized HOOC-PLA-NS and amino-functionalized $\mathrm{H}_{2} \mathrm{~N}$-PLA-NS, were prepared via a solvent evaporation method (Scheme 1). The mean particle size, PDI, $\zeta$ potential, and maximum ALR of the Abam-PLA nanoparticles are

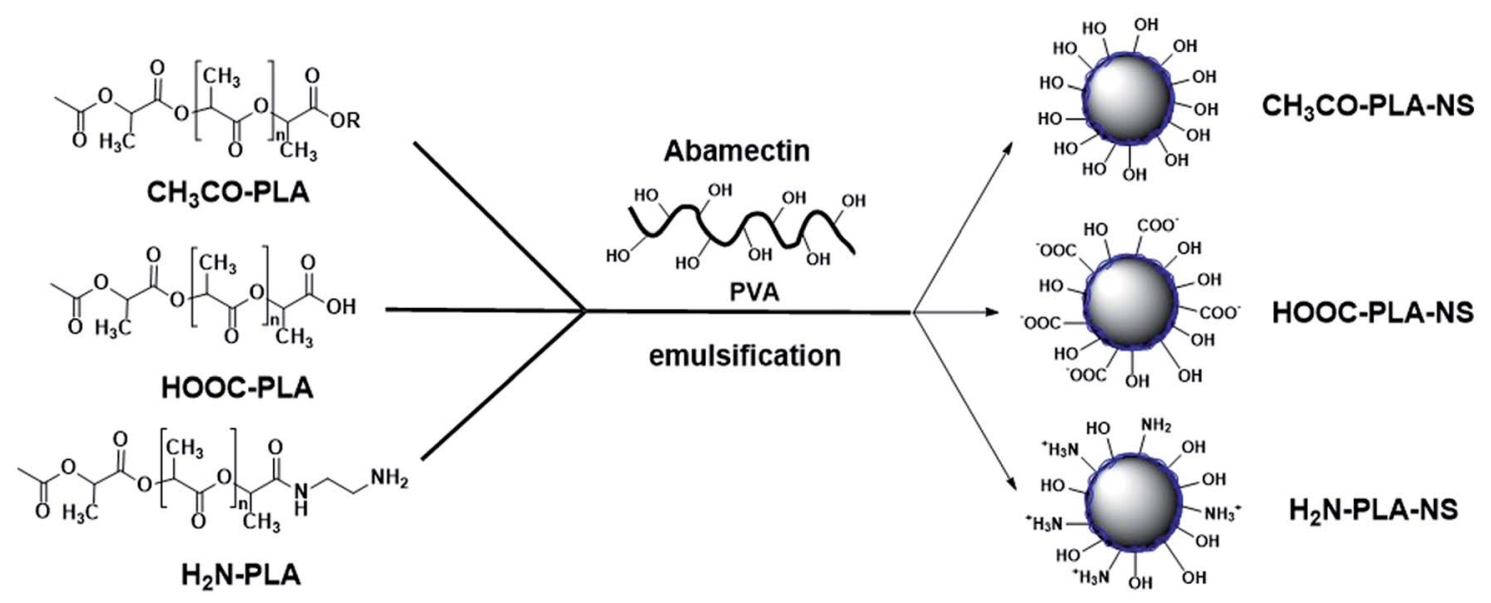

Scheme 1 Schematic illustration of the preparation for $\mathrm{CH}_{3} \mathrm{CO}-\mathrm{PLA}-\mathrm{NS}$, HOOC-PLA-NS, and $\mathrm{H}_{2} \mathrm{~N}-\mathrm{PLA}-\mathrm{NS}$ by emulsification. 


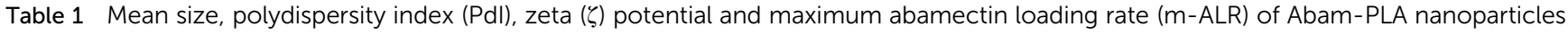

\begin{tabular}{lllr}
\hline Samples & Mean size $(\mathrm{nm})$ & PdI & $\zeta$ potential $(\mathrm{mV})$ \\
\hline CH $_{3}$ CO-PLA-NS & $543.3 \pm 7.0$ & $0.02 \pm 0.11$ & $-14.1 \pm 0.6$ \\
HOOC-PLA-NS & $456.4 \pm 21.5$ & $0.05 \pm 0.04$ & $-18.6 \pm 0.5$ \\
H $_{2}$ N-PLA-NS & $429.3 \pm 16.4$ & $0.04 \pm 0.03$ & $9.4 \pm 0.2$
\end{tabular}
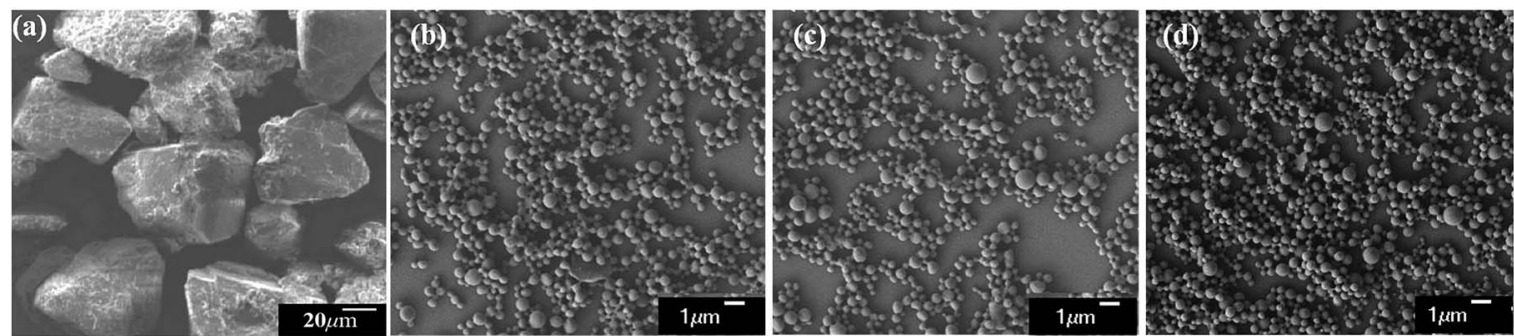

Fig. 2 The SEM images of active abamectin (a), $\mathrm{CH}_{3} \mathrm{CO}-\mathrm{PLA}-\mathrm{NS}$ (b), HOOC-PLA-NS (c) and $\mathrm{H}_{2} \mathrm{~N}-\mathrm{PLA}-\mathrm{NS}$ (d). The scale bar is indicated in each image.

investigated by DLS, and the results were summarized in Table 1. The low PdI of the Abam-PLA nanoparticles (all less than 0.1) implied that they are highly monodispersed (Fig. S1†). The $\zeta$ potentials of $\mathrm{CH}_{3} \mathrm{CO}-\mathrm{PLA}-\mathrm{NS}$, HOOC-PLA-NS, and $\mathrm{H}_{2} \mathrm{~N}-\mathrm{PLA}-\mathrm{NS}$ were $-14.1 \pm 0.6,-18.6 \pm 0.5$, and $9.4 \pm 0.2$, respectively (Fig. S2 $\dagger$ ). The negative $\zeta$ potential of $\mathrm{CH}_{3} \mathrm{CO}-\mathrm{PLA}-\mathrm{NS}$ suggested that slight hydrolysis of PLA might occur to produce carboxylic acid during its preparation. The maximum ALR of the three types of Abam-PLA nanoparticles was nearly 50\%, and the specific ALR can be obtained below m-ALR, indicating that the functional groups of PLA derivatives have negligible effect on pesticide loading. SEM images afforded higher spatial resolution of the morphology and precise size of the nanoparticles, and are provided in Fig. 2. These images confirmed that the Abam-PLA nanoparticles are nearly uniform spheres with an average diameter of around $450 \mathrm{~nm}$. The statistical distributions of nanoparticle sizes from the SEM images are also shown in Fig. S3. $\dagger$ These results agreed with DLS data.

\section{Stability of Abam-PLA nanoparticles under different temperature and $\mathrm{pH}$ condition}

Stability of pesticide formulations is very important. The stability of Abam-PLA nanoparticles under various temperatures $\left(4{ }^{\circ} \mathrm{C}\right.$, $25{ }^{\circ} \mathrm{C}$ and $54{ }^{\circ} \mathrm{C}$ ) and $\mathrm{pH}$ condition (5.0, 7.0, and 9.0) was investigated. The DLS mean size and PDI are adopted to evaluate the storage stability at different temperature. As shown in Fig. S4 and $55, \dagger$ the mean size and PDI presented negligible variation at $4{ }^{\circ} \mathrm{C}$ and $25{ }^{\circ} \mathrm{C}$. At high temperature $\left(54{ }^{\circ} \mathrm{C}\right)$, the mean size had small increase, and the PDI exhibited moderate increase, presumably because $54{ }^{\circ} \mathrm{C}$ is very close to the glass state temperature of PLA (approximately $60{ }^{\circ} \mathrm{C}$ ). The contents of abamectin analysed by HPLC in Abam-PLA nanoparticles at different storage temperature kept almost unchanged. These results suggest Abam-PLA nanoparticles are very stable at low and room temperature, and have a little aggregation at high temperature.
The mean size and PDI of Abam-PLA nanoparticles showed very small change at $\mathrm{pH}$ 5.0, 7.0, and 9.0, indicating they have good stability at different $\mathrm{pH}$ (Fig. S5 and S6†).

\section{Photodegradation behavior of Abam-PLA nanoparticles}

Abamectin is very sensitive to the UV light. In general, the photostability of abamectin is improved by encapsulation. The timedependent response curves of the photodegradation rate of active abamectin and Abam-PLA nanoparticles are illustrated in Fig. S7. $\uparrow$ The photodegradation rate of active abamectin is relatively fast, with almost $50 \%$ decomposing after $38 \mathrm{~h}$ of continuous UV irradiation. In contrast, very little of the abamectin loaded in the Abam-PLA nanoparticles had decomposed after the same time. However, abamectin from the nanoparticles does decompose with lengthening irradiation time. These results indicate that abamectin loaded in Abam-PLA nanoparticles possesses higher photostability than that of active abamectin, probably resulting from the protection of PLA as a carrier.

\section{Density of functional groups on the surface of Abam-PLA nanoparticles}

The functional groups on the surface of nanoparticles might play a vital role in their adhesion to foliage via several kinds of interactions involving functional groups, such as hydrogen bond and electrostatic attraction/repulsion. The amounts of carboxylic acid and amine groups on the surface of Abam-PLA nanoparticles were calculated based on the polyelectrolyte titration method. ${ }^{35}$ The determined densities of carboxylic groups on the nanoparticle surfaces were $0.8,4.6$, and 0.5 per $\mathrm{nm}^{-2}$ for $\mathrm{CH}_{3} \mathrm{CO}-\mathrm{PLA}$ NS, HOOC-PLA-NS, and $\mathrm{H}_{2} \mathrm{~N}$-PLA-NS, respectively (Table S1 $\dagger$ ). The carboxylic acid groups on the surface of $\mathrm{CH}_{3} \mathrm{CO}-\mathrm{PLA}-\mathrm{NS}$ and $\mathrm{H}_{2} \mathrm{~N}$-PLA-NS resulted from slight decomposition of PLA during ultrasonication, ${ }^{35,36}$ which was also confirmed by the negative $\zeta$ potential of $\mathrm{CH}_{3} \mathrm{CO}-\mathrm{PLA}-\mathrm{NS}$. The density of amine groups on the 


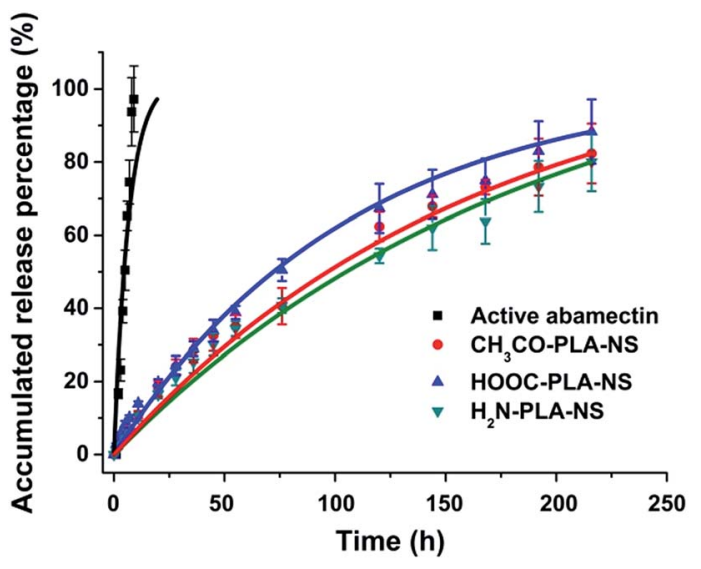

Fig. 3 Sustained release profiles of active abamectin and abamectin provided by Abam-PLA nanoparticles. The accumulated release percentages were obtained against time from the sustained release amounts.

surface of $\mathrm{H}_{2} \mathrm{~N}$-PLA-NS was 2.8 per $\mathrm{nm}^{-2}$, almost 5.6 times that of carboxylic acid groups (Table $\mathrm{S} 1 \dagger$ ). Therefore, the overall charge on the $\mathrm{H}_{2} \mathrm{~N}$-PLA-NS surface should be positive, which agrees well with its $\zeta$ potential.

\section{Sustained release behaviour of Abam-PLA nanoparticles}

The sustained release profiles of active abamectin and AbamPLA nanoparticles are presented in Fig. 3. All the Abam-PLA nanoparticles exhibited slower release rates than that of active abamectin, indicating that PLA as a carrier is beneficial to prolong the leaching time and increase the utilization efficiency of abamectin. The release rate of active abamectin was relatively fast, and it was completely released within $24 \mathrm{~h}$. However, the release rates of Abam-PLA nanoparticles were gradual, and the release was still continuous after nearly 10 days. The sustained release profiles of the three types of Abam-PLA nanoparticles are quite similar, implying that the functional groups of PLA derivatives have a small effect on nanoparticle release behaviour. The accumulated release percentages obey first-order kinetics, with $R^{2}$ values over 0.99 (Table $\mathrm{S} 2 \dagger$ ). These results indicate that three types of Abam-PLA nanoparticles display favorable sustained release behavior.

\section{Deposition and adhesion of Abam-PLA nanoparticles on the surface of cucumber foliage}

The efficient deposition and strong adhesion of pesticides on the surface of foliage are very important to minimize loss of the pesticides and raise utilization efficiency. The wetting behavior of Abam-PLA nanoparticles on the surface of cucumber foliage was investigated by measuring CA. The CA of deionized water was measured as a control. The CA images are shown in Fig. S8, $\uparrow$ and the data are summarized in Table S3. $\dagger$ The calculated CA values on the left of the water droplets were 65.8 $\pm 6.1^{\circ}, 70.1 \pm 1.4^{\circ}$, and $70.7 \pm 6.2^{\circ}$ for $\mathrm{CH}_{3} \mathrm{CO}$-PLA-NS, HOOCPLA-NS, and $\mathrm{H}_{2} \mathrm{~N}-\mathrm{PLA}-\mathrm{NS}$, respectively, and those for the right were $69.5 \pm 10.6^{\circ}, 74.1 \pm 11.2^{\circ}$, and $69.0 \pm 1.7^{\circ}$, respectively. Meanwhile, under the same conditions, the CAs on the left and right of a deionized water droplet on cucumber foliage were 76.7 $\pm 7.4^{\circ}$ and $74.8 \pm 7.5^{\circ}$, respectively. These results indicate that the Abam-PLA nanoparticles possessed slightly improved wettability on cucumber foliage compared with that of water.

It is very difficult to probe the deposition and adhesion behavior of pesticides on live cucumber foliage by conventional methods. In this study, fluorescence imaging was used to investigate the deposition and adhesion behavior of the nanoparticles because of its advantages of high sensitivity, convenience, and live sample scanning. To effectively obviate the interference of spontaneous fluorescence (mainly from chlorophyll inside the leaves), rhodamine $6 \mathrm{G}$ was encapsulated within the
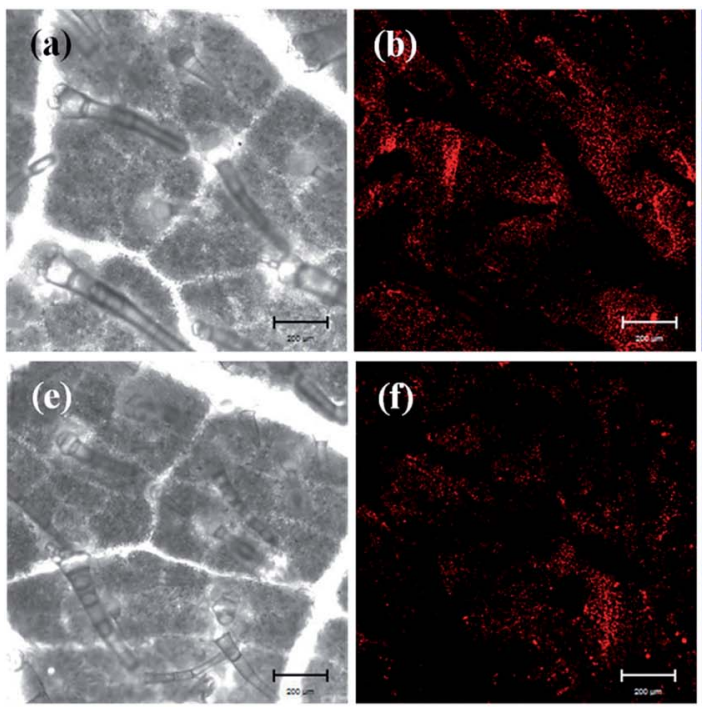
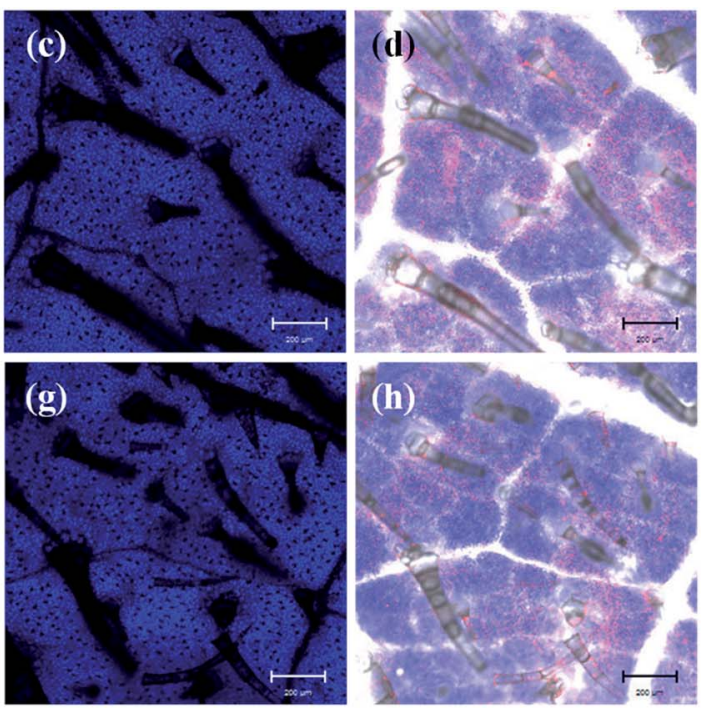

Fig. 4 Confocal fluorescence images of $\mathrm{H}_{2} \mathrm{~N}-\mathrm{PLA}-\mathrm{NS}$ on the surface of cucumber foliage. (a-d) Images before washing, and (e-h) images after washing. (a and e) Bright-field images, (b and f) $\mathrm{H}_{2} \mathrm{~N}$-PLA-NS fluorescence imaging (excited at $555 \mathrm{~nm}$, detected at $580 \mathrm{~nm}$ ), (c and g) chlorophyll fluorescence imaging (excited at $630 \mathrm{~nm}$, detected at $670 \mathrm{~nm}$ ), and ( $\mathrm{d}$ and h) overlays of images. The scale bar is $200.0 \mu \mathrm{m}$ in all images. 

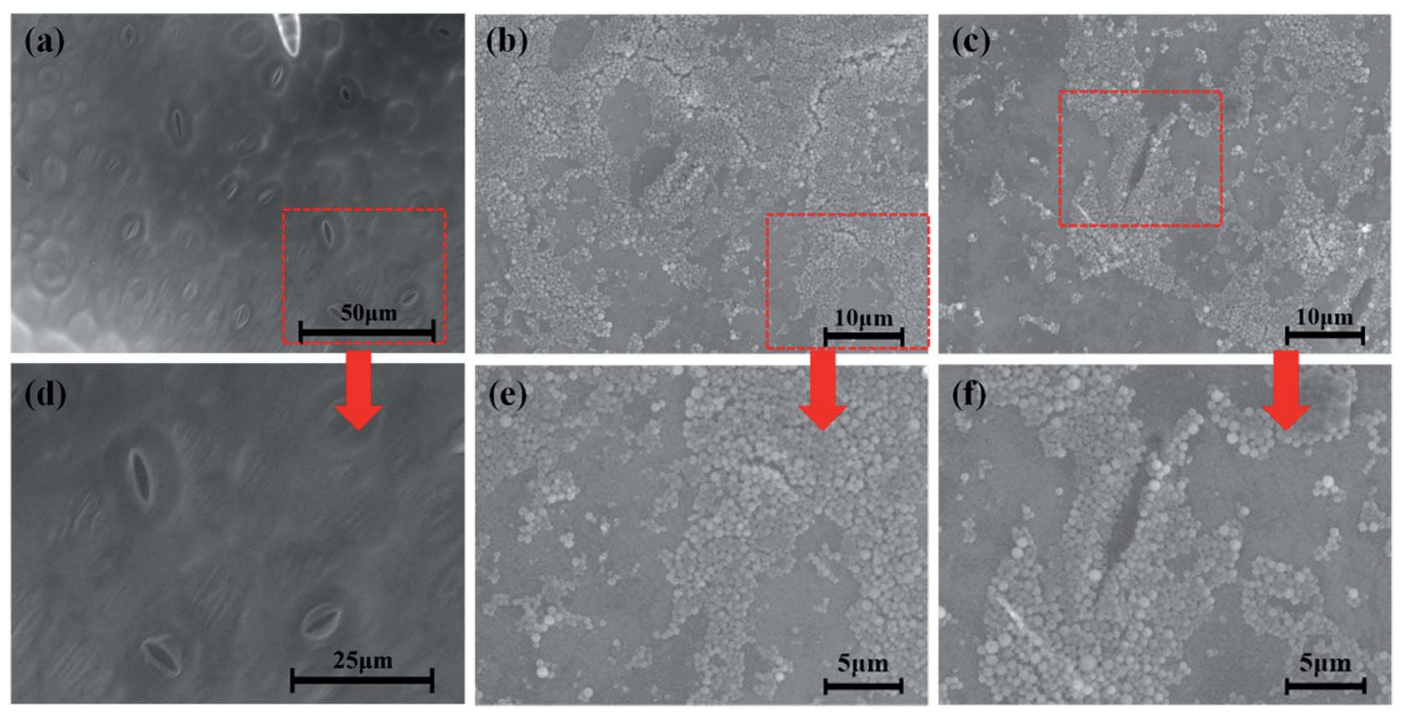

Fig. 5 ESEM images of $\mathrm{H}_{2} \mathrm{~N}$-PLA-NS on the surface of cucumber leaves. (a) Foliage image using nanoparticles as a control, (b) image with $\mathrm{H}_{2} \mathrm{~N}$ PLA-NS, (c) image after washing, and ( $d-f)$ magnified images in indicated specific regions in (a), (b) and (c), respectively.

nanoparticles to obtain fluorescent Abam-PLA nanoparticles. We assumed that the properties of the fluorescent Abam-PLA nanoparticles were the same as those of the Abam-PLA nanoparticles because less than $0.2 \%(\mathrm{w} / \mathrm{w})$ rhodamine $6 \mathrm{G}$ calculated from fluorescence intensity was included in the fluorescent Abam-PLA nanoparticles. As shown in Fig. 4, S9 and S10, $\dagger$ Abam-PLA nanoparticles were deposited everywhere on the cucumber foliage surface including the wax layer, tomenta, and nervure. To test the adhesion of the nanoparticles to foliage, the leaves were flushed with deionized water. Numerous Abam-PLA nanoparticles remained on the leaves after flushing, indicating they have an affinity for cucumber foliage.

To visualize the leaf-nanoparticle systems in spatial dimensions, ESEM was used to characterize the deposition and adhesion characteristics of Abam-PLA nanoparticles on the surface of cucumber foliage. As clearly illustrated in Fig. 5, S11 and $\mathrm{S} 12, \dagger$ large numbers of Abam-PLA nanoparticles were evenly deposited everywhere on the leaf surface including wax layer, tomenta, and nervure. More interestingly, numerous nanoparticles were observed in stomata and nearby. Given that the Abam-PLA nanoparticles are far smaller than the stomata, the Abam-PLA nanoparticles might easily enter the leaf via a "stomata pathway", and subsequently be transported inside the foliage. After washing with deionized water, numerous Abam-PLA nanoparticles remained, confirming the nanoparticles and cucumber foliage interacted. These results are consistent with those of fluorescence imaging.

The abamectin retention rate after washing was used to roughly evaluate the adhesion capability of the nanoparticles to cucumber foliage. Because of the experimental limitations, it was impossible to quantify the retention rate of Abam-PLA nanoparticles on cucumber foliage after washing by LSCM and ESEM. Therefore, we used in vivo foliage imaging to evaluate retention rate. The variation of fluorescence intensity on a specific leaf before $\left(I_{0}\right)$ and after washing $(I)$ was measured, and the retention rate $\left(I / I_{0}\right)$ was determined as the difference of fluorescence intensity. As shown in Fig. 6 and 7, the retention rates were $43 \%, 38 \%$, and $58 \%$ for $\mathrm{CH}_{3}$ CO-PLA-NS, HOOC-PLANS, and $\mathrm{H}_{2} \mathrm{~N}$-PLA-NS, respectively, indicating that $\mathrm{H}_{2} \mathrm{~N}$-PLA-NS exhibited better adhesion capability to cucumber foliage than the other nanoparticles. At the same time, HPLC was used to analyze the abamectin concentration and calculate the retention rates conventionally. The retention rates obtained from HPLC analysis were $41 \%, 33 \%$, and $61 \%$ for $\mathrm{CH}_{3}$ CO-PLA-NS, HOOC-PLA-NS, and $\mathrm{H}_{2}$ N-PLA-NS, respectively, agreeing well with the fluorescence intensity data. In addition, the retention rates for commercial WDG and EC calculated by HPLC were $28 \%$ and $43 \%$, respectively (Fig. 7 ). These results imply that the $\mathrm{H}_{2} \mathrm{~N}$-PLA-NS adhere more strongly to cucumber foliage than WDG and EC, and regulatable adhesion can be achieved simply by changing the functional groups on the surface of the nanoparticles.

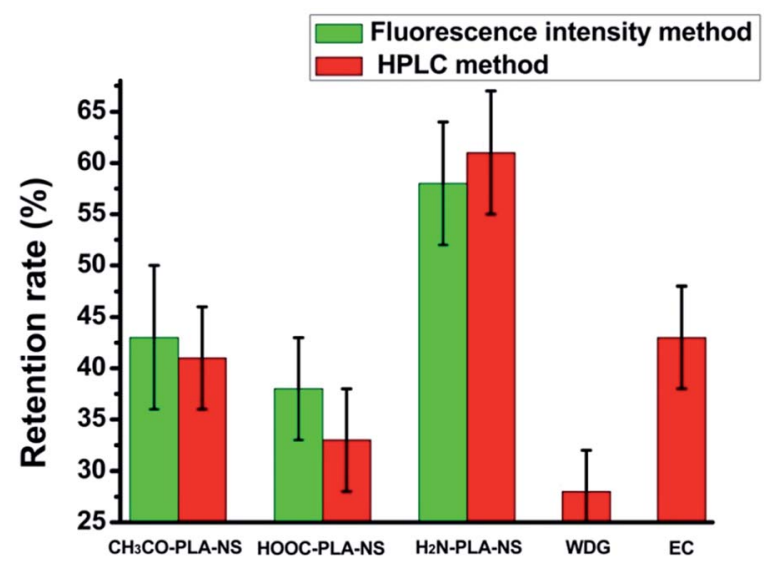

Fig. 6 Retention rates of Abam-PLA nanoparticles determined from fluorescence intensity and HPLC and commercially available formulations determined by HPLC on the surface of cucumber leaves. 

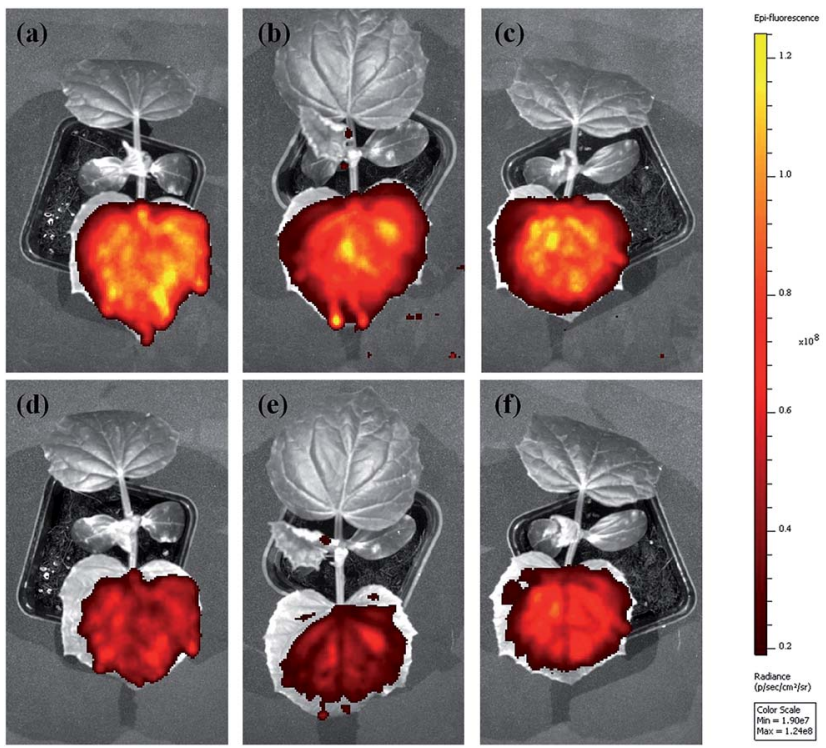

Fig. 7 Living cucumber plant imaging of Abam-PLA nanoparticles. (ac) Images of $\mathrm{CH}_{3} \mathrm{CO}-\mathrm{PLA}-\mathrm{NS}$, HOOC-PLA-NS, and $\mathrm{H}_{2} \mathrm{~N}-\mathrm{PLA}-\mathrm{NS}$, respectively. (d-f) Images corresponding to $\mathrm{CH}_{3} \mathrm{CO}-\mathrm{PLA}-\mathrm{NS}$, HOOCPLA-NS, and $\mathrm{H}_{2} \mathrm{~N}-\mathrm{PLA}-\mathrm{NS}$ after washing, respectively.

\section{Interaction mechanism of Abam-PLA nanoparticles with the cucumber foliage surface}

As a typical weakly hydrophilic surface, there are several kinds of glycosides including hydroxyl groups on cucumber foliage. ${ }^{37}$ In addition, the wax layer consists of many kinds of higher fatty acids, higher fatty alcohols, and higher fatty aldehydes. ${ }^{38}$ These polar groups on the cucumber foliage surface may interact with the functional groups on the Abam-PLA nanoparticle surface (Scheme 2). $\mathrm{CH}_{3} \mathrm{CO}-\mathrm{PLA}-\mathrm{NS}$ binds to the cucumber foliage surface by hydrogen bond through the hydroxyl groups on $\mathrm{CH}_{3} \mathrm{CO}-\mathrm{PLA}-\mathrm{NS}$ and hydroxyl or carboxylic acid groups on the foliage surface. Although there is hydrogen bond between HOOCPLA-NS and the cucumber foliage surface, electrostatic repulsion could weaken their interaction. Besides hydrogen bond, because the surface charge of $\mathrm{H}_{2} \mathrm{~N}$-PLA-NS is positive, the binding between $\mathrm{H}_{2} \mathrm{~N}$-PLA-NS and the cucumber foliage surface could be strengthened by electrostatic attraction. Moreover, the aldehyde groups on the foliage surface could react with the amine groups of these nanoparticles to form covalent Schiff bases. These multimodal interactions between $\mathrm{H}_{2} \mathrm{~N}$-PLA-NS and the cucumber foliage surface result in strong adhesion between them.

\section{Biological efficacy evaluation}

In this study, the leaf dipping method was used to evaluate the indoor toxicity of Abam-PLA nanoparticles, WDG, and EC. The results are shown in Table 2. Determined $\mathrm{LC}_{50}$ values were 3.95, $5.85,3.50,4.63$, and 3.73 for $\mathrm{CH}_{3} \mathrm{CO}-\mathrm{PLA}-\mathrm{NS}$, HOOC-PLA-NS,

Table 2 Indoor toxicity of Abam-PLA nanoparticles and commercially available formulations WDG and EC

\begin{tabular}{llll}
\hline Samples & Regressive equation & $R^{2}$ & $\mathrm{LC}_{50}(\mathrm{ppm})$ \\
\hline $\mathrm{CH}_{3}$ CO-PLA-NS & $y=4.27+0.95 x$ & 0.94 & 3.95 \\
HOOC-PLA-NS & $y=4.56+0.74 x$ & 0.89 & 5.85 \\
$\mathrm{H}_{2}$ N-PLA-NS & $y=4.60+0.73 x$ & 0.94 & 3.50 \\
WDG & $y=4.17+1.25 x$ & 0.97 & 4.63 \\
EC & $y=4.49+0.89 x$ & 0.99 & 3.73
\end{tabular}

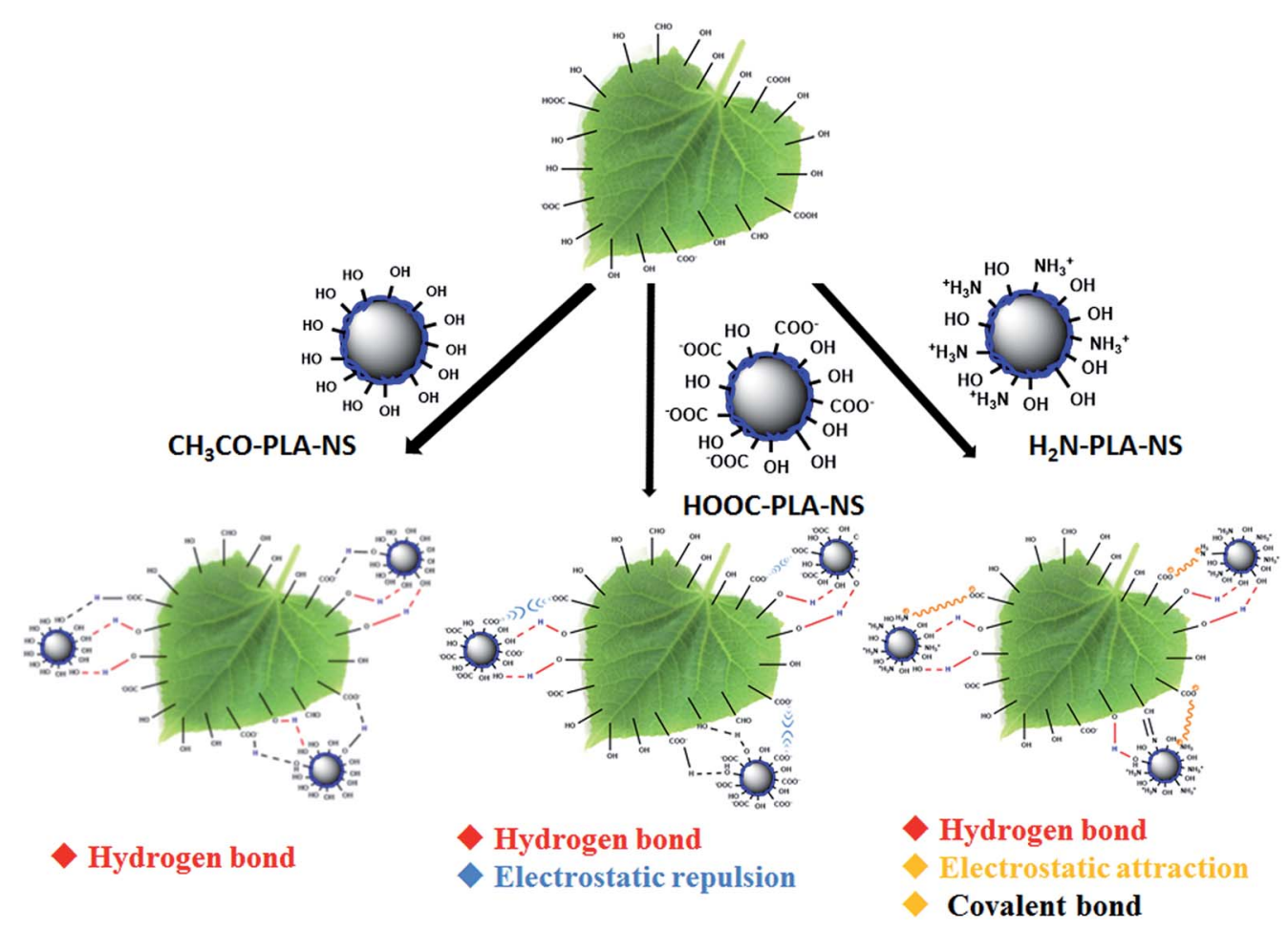

Scheme 2 Schematic illustration of the interaction between Abam-PLA nanoparticles and the cucumber foliage surface. 
$\mathrm{H}_{2} \mathrm{~N}$-PLA-NS, WDG, and EC, respectively. There are no significant differences of indoor toxicity among these samples, indicating that the toxicity of abamectin loaded in the Abam-PLA nanoparticles is preserved, and comparable to that of commercially available formulations. Given the many kinds of loss of conventional formulations under complex outdoor conditions, the effective utilization efficiency of abamectin should be greatly improved using formulations with strong leaf adhesion, such as $\mathrm{H}_{2} \mathrm{~N}-\mathrm{PLA}-\mathrm{NS}$.

\section{Conclusion}

In summary, three types of abamectin-loaded PLA nanoparticles ( $\mathrm{CH}_{3} \mathrm{CO}-\mathrm{PLA}-\mathrm{NS}$, HOOC-PLA-NS, and $\mathrm{H}_{2} \mathrm{~N}-\mathrm{PLA}-\mathrm{NS}$ ) with various functional groups were prepared by solvent evaporation. The nanoparticles were nearly uniform spheres with a diameter of around $450 \mathrm{~nm}$. The maximum ALR of the nanoparticles after optimization was around 50\%. The Abam-PLA nanoparticles exhibited excellent continuous release behavior and higher photostability capability than active abamectin alone because of inclusion in PLA.

The deposition and adhesion of Abam-PLA nanoparticles on the surface of cucumber foliage were investigated by confocal fluorescence imaging, ESEM, in vivo foliage imaging and HPLC analysis. $\mathrm{CH}_{3}$ CO-PLA-NS, HOOC-PLA-NS, and $\mathrm{H}_{2} \mathrm{~N}$-PLA-NS were deposited and adhered favorably on the surface of cucumber foliage. The adhesion strength to cucumber foliage of the nanoparticles was: $\mathrm{H}_{2} \mathrm{~N}$-PLA-NS $>\mathrm{CH}_{3} \mathrm{CO}-\mathrm{PLA}-\mathrm{NS}>$ HOOC-PLA-NS. $\mathrm{H}_{2} \mathrm{~N}$-PLA-NS interacted with different groups on cucumber foliage by hydrogen bonding, electrostatic attraction and covalent bonding. Meanwhile, HOOC-PLA-NS interacted with cucumber leaves through hydrogen bonding and electrostatic repulsion, leading to decreased adhesion strength compared with that of $\mathrm{H}_{2} \mathrm{~N}$-PLA-NS. The adhesion strength strongly depended on the functional groups on the nanoparticle surface, and was easily regulated by varying functional groups. These results reveal a route to develop smart pesticide nanoparticles with adhesion regulation through light, heat, or $\mathrm{pH}$ for different purposes in crop protection. Using these smart pesticide nanoparticles, we envision that pesticide losses could be substantially lowered and effective utilization efficiency improved, leading to decreased spraying dosage, residue, and pollution in food and the environment.

\section{Acknowledgements}

This work was financially supported by Chinese Academy of Agricultural Sciences (2060302, 2015ZL042), National Key Basic Research Program of China (973 Program, 2014CB932200), and 1000 talents plan.

\section{References}

1 What is a pesticide? U.S. Environmental Protection Agency, 2007.

2 International Code of Conduct on the Distribution and Use of Pesticides. Food and Agriculture Organization of the United Nations, 2007.
3 C. Lamberth, S. Jeanmart, T. Luksch and A. Plant, Science, 2013, 341, 742.

4 A. Grube, D. Donaldson, T. Kiely and L. Wu, Pesticides Industry Sales and Usage, U.S. Environmental Protection Agency, 2011.

5 http://www.epa.gov/pesticides/cumulative.

6 Agricultural Statistics, United States Department of Agriculture, United States Government Printing Office, Washington, DC, 1992.

7 C. F. Moffat and K. J. Whittle, Environmental Contaminants in Food, Sheffield Academic Press, Sheffield, 1999.

8 S. M. Bradberry, A. T. Proudfoot and V. J. Allister, Toxicol. Rev., 2004, 23, 65.

9 F. Worek, M. Koller, H. Thiermann and L. Szinicz, Toxicology, 2005, 214, 182.

10 P. Eyer, Toxicol. Rev., 2003, 22, 165.

11 M. Eddleston, P. Eyer, F. Worek, F. Mohamed, L. Senarathna, L. V. Meyer, E. Juszczak, A. Hittarage, S. Azhar, W. Dissanayake, M. H. R. Sheriff, L. Szinicz, A. H. Dawson and N. A. Buckley, Lancet, 2005, 366, 1452.

12 M. Eddleston, F. Worek, P. Eyer, H. Thiermann, L. V. Meyer, K. Jeganathan, M. H. R. Sheriff, A. H. Dawson and N. A. Q. Buckley, J. Med., 2009, 102, 785.

13 K. Fenner, S. Canomica, L. P. Wackett and M. Elsner, Science, 2013, 341, 752.

14 E. Malaj, M. Grote, R. Kühne, C. P. Mondy, P. U. Polatera, W. Brack and R. F. Schäfer, Proc. Natl. Acad. Sci. U. S. A., 2014, 111, 9549.

15 H. R. Köhler and R. Triebskorn, Science, 2013, 341, 759.

16 M. Nuruzzaman, M. M. Rahman, Y. Liu and R. Naidu, J. Agric. Food Chem., 2016, 64, 1447.

17 J. Morris, J. Willis, D. D. Martinis, B. Hansen, H. Laursen, J. R. Sintes, P. Kearns and M. Gonzalez, Nat. Nanotechnol., 2011, 6, 73.

18 R. Nair, S. H. Varghese, B. G. Nair, T. Maekawa, Y. Yoshida and D. S. Kumar, Plant Sci., 2010, 179, 154.

19 R. S. Kookana, A. B. A. Boxall, P. T. Reeves, R. Ashauer, S. Beulke, Q. Chaudhry, G. Cornelis, T. F. Fernandes, J. Gan, M. Kah, I. Lynch, J. Ranville, C. Sinclair, D. Spurgeon, K. Tiede and P. V. d. Brink, J. Agric. Food Chem., 2014, 62, 4227.

20 L. F. Fraceto, R. Grillo, G. A. de Medeiros, V. Scognamiglio, G. Rea and C. Bartolucci, Front. Environ. Sci. Eng., 2016, 4, 20.

21 A. Gogos, K. Knauer and T. D. Bucheli, J. Agric. Food Chem., 2012, 60, 9781.

22 V. Ghormade, M. V. Deshpande and K. M. Paknikar, Biotechnol. Adv., 2011, 29, 792.

23 L. R. Khot, S. Sankaran, J. M. Maja, R. Ehsani and E. W. Schuster, Crop Prot., 2012, 35, 64.

24 M. Kah and T. Hofmann, Environ. Int., 2014, 63, 224.

25 S. Norman and H. D. Chen, Ind. Biotechnol., 2012, 8, 340.

26 A. L. Boehm, I. Martinon, R. Zerrouk, E. Rump and H. Fessi, J. Microencapsulation, 2003, 20, 433.

27 H. F. Zhang, D. Wang, R. Butler, N. L. Campbell, J. Long, B. Tan, D. J. Duncalf, A. J. Foster, A. Hopkinson, D. Taylor, D. Angus, A. I. Cooper and S. P. Rannard, Nat. Nanotechnol., 2008, 3, 506. 
28 P. Bordes, E. Pollet and L. Aveérous, Prog. Polym. Sci., 2009, 34, 125.

29 Z. Z. Li, S. A. Xu, L. X. Wen, F. Liu, A. Q. Liu, Q. Wang, H. Y. Sun, W. Yu and J. F. Chen, J. Controlled Release, 2006, 111, 81.

30 D. Li, B. Liu, F. Yang, X. Wang, H. Shen and D. Wu, Carbohydr. Res., 2016, 136, 341.

31 B. Liu, Y. Wang, F. Yang, X. Wang, H. Shen, D. Wu and H. Cui, Colloids Surf., B, 2016, 144, 38.

32 X. Jia, W. Sheng, W. Li, Y. Tong, Z. Liu and F. Zhou, ACS Appl. Mater. Interfaces, 2014, 6, 19552.

33 G. R. Lankas and L. R. Gordon, Ivermectin and Abamectin, Springer-Verlag, NY, 1989.
34 L. S. Crouch, W. F. Feely, B. H. Arison, W. J. A. VandenHeuvel, L. F. Colwell, R. A. Searns, W. F. Klines and P. G. Wislockit, J. Agric. Food Chem., 1991, 39, 1310.

35 M. Urban, B. Freisinger, O. Ghazy, R. Staff, K. Landfester, D. Crespy and A. Musyanovych, Macromolecules, 2014, 47, 7194.

36 M. Urban, A. Musyanovych and K. Landfester, Macromol. Chem. Phys., 2009, 210, 961.

37 Cucumis sativus (cucumber)-Derived Ingredients as Used in Cosmetics. Cosmetic Ingredient Review, 2012, www.cirsafety.org/sites/default/files/cucum032012tent.pdf.

38 P. J. Holloway, Pestic. Sci., 1970, 1, 156. 